\title{
The effect of obstructive sleep apnea-hypopnea syndrome on acute myocardial infarction
}

\author{
Zhang $\mathrm{W}^{1}$, Sun $\mathrm{Y}^{1}$, Li $\mathrm{T}^{1}$, Zhang $\mathrm{G}^{1}$, Wang $\mathrm{Y}^{1}$, Sun $\mathrm{H}^{2}$ \\ Department of Cardiology, Chinese PLA General Hospital, Beijing China.870824370@qq.com
}

\begin{abstract}
Background and objectives: Obstructive sleep apnea-hypopnea syndrome (OSAHS) is the most clinically common type of sleep-related breathing disorders. In this study, the effect of OSAHS on ST segment elevation myocardial infarction (STEMI) was investigated.

Methods: Seventy-five patients with STEMI were included in this study. The patients were divided into two groups:

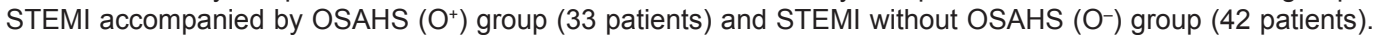
The differences of the clinical characteristics between the two groups were compared. The relationship between oxyhemoglobin desaturation index (ODI) and Gensini Score, and the relationships between OSAHS and clinical parameters were analyzed by a regression analysis.

Results: AMI mainly occurred from $10 \mathrm{pm}$ to $6 \mathrm{am}$ in the $\mathrm{O}^{+}$group $(45.5 \%)$ and from 6 am to $2 \mathrm{pm}$ in the $\mathrm{O}^{-}$ group (52.3\%). The peak of serous creatine kinase (CK), high-sensitivity C-reactive protein (hs-CRP), N-terminal Pro-brain natriuretic peptide (NT-proBNP), and left ventricle end-diastolic volume index (LVEDVI) were significantly increased in the $\mathrm{O}^{+}$group compared to the $\mathrm{O}^{-}$group, while the left ventricular ejection fraction (LVEF) were significantly decreased. The regression analysis showed that ODI was positively correlated with Gensini Score, while serous CK, hs-CRP, NT-proBNP, and OSAHS were independently associated with left ventricular insufficiency (LVI), and the incidence of LVI in $\mathrm{O}^{+}$group was 5.8 times as $\mathrm{O}^{-}$group.

Conclusions: InSTEMI patients with OSAHS, myocardial infarction mainly occurred from $10 \mathrm{pm}$ to $6 \mathrm{am}$, and the incidence of LVI was significantly higher than STEMI patients without OSAHS (Tab. 5, Fig. 2, Ref. 26). Full Text in PDF www.elis.sk. Key words: sleep apnea syndromes, acute myocardial infarction, coronary artery disease.
\end{abstract}

Obstructive sleep apnea-hypopnea syndrome (OSAHS) is the most common type of sleep-related breathing disorders, which was caused by throat obstruction $(1,2)$. The syndrome associates somnolence and one or two of the following symptoms: severe snoring, nocturnal respiratory arrest, repeated nocturnal awakening, non-recuperative sleep, diurnal fatigue, and altered concentration (34). OSAHS may act to cause and promote the progression of hypertension, coronary artery disease (CAD), acute myocardial infarction (AMI) and cerebral vascular disease $(1,5)$. It is reported that its incidences in adult women is $2 \%$, and in adult men is $4 \%(6)$. While in China, its incidence is about $3.62 \%$ in people beyond 30 years, which means that there are more than 47 million of patients in China by now (7).

Numerous studies showed that OSAHS is closely associated with the development and progression of CAD. The changes of hemodynamics, enhancement of the sympathetic activity, and oxidative stress that are caused by OSAHS can accelerate the process of artherosclerosis $(8,9)$. Peker et al $(10)$ reported that

${ }^{1}$ Department of Cardiology, Chinese PLA General Hospital, Beijing China, and ${ }^{2}$ State Key Laboratory of Respiratory Diseases, The First Affiliated Hospital of Guangzhou Medical College, Guangzhou Guangdong Province, China

Address for correspondence: $\mathrm{Y}$. Wang, MD, Department of Cardiology, Chinese PLA General Hospital, Beijing 100853, Beijing, China. Phone: +86.10 .66887329 , Fax: +86.10 .66939510$

Supported by: The Special Research Foundation of the National Nature Science Foundation of China (30740800). the incidence of OSAHS is higher in the patients with CAD than in normal people, and OSAHS can raise the mortality of angiocardiopathy, while patients treated by continuous positive airway pressure (CPAP) can reverse this state. The results of Peker et al (10) also demonstrated that OSAHS is an independent risk factor of hypertensive disease, CAD and AMI. However, the effect of OSAHS on AMI in Chinese patients has seldom been reported.

In the present study, the data of 75 Chinese patients with ST segment elevation myocardial infarction (STEMI), which were admitted to our Intensive Care Unit from March 2007 to December 2008 and performed coronary angiography and overnight oximetry, were analyzed retrospectively. The differences of the clinical characteristics between the STEMI patients accompanied OSAHS and STEMI patients without OSAHS were compared. The relationship between oxyhemoglobin desaturation index (ODI) and Gensini Score (11) were analyzed by simple linear regression analysis. The relationship between OSAHS and clinical parameters were analyzed by binary logistic regression analysis.

\section{Patients and methods}

\section{Patients}

From March 2007 to December 2008, 75 patients with STEMI were treated and underwent coronary angiography and overnight oximetry at the Intensive Care Unit in our hospital. The patients were divided into two groups: STEMI accompanied by OSAHS $\left(\mathrm{O}^{+}\right)$ 
Tab. 1. Comparison of demographic data between the two groups.

\begin{tabular}{lccc}
\hline Characteristics & $\mathrm{O}^{+}$group $(\mathrm{n}=33)$ & $\mathrm{O}^{-}$group $(\mathrm{n}=42)$ & $\mathrm{p}$ value \\
\hline Sex & & & 0.432 \\
Male & 26 & 36 & \\
Female & 7 & 6 & \\
Age $(\mathrm{y})$ & $56.6 \pm 12.4$ & $56.1 \pm 12.9$ & 0.893 \\
BMI $(\mathrm{kg} / \mathrm{m} 2)$ & $26.1 \pm 3.4$ & $24.6 \pm 2.9$ & 0.629 \\
Time to therapy $(\mathrm{h})$ & $5.6 \pm 2.9$ & $5.2 \pm 3.0$ & 0.770 \\
Hypertension $(\mathrm{n})$ & 19 & 14 & 0.036 \\
\hline
\end{tabular}

Tab. 2. Comparison of serological data between the two groups.

\begin{tabular}{lccc}
\hline Characteristics & $\mathrm{O}^{+}$group $(\mathrm{n}=33)$ & $\mathrm{O}^{-}$group $(\mathrm{n}=42)$ & p value \\
\hline CK $(\mathrm{U} / \mathrm{L})$ & $3930.7 \pm 3100.6$ & $2918.5 \pm 2040.4$ & 0.008 \\
hs-CRP $(\mathrm{mg} / \mathrm{L})$ & $2.30 \pm 1.64$ & $1.13 \pm 0.80$ & 0.004 \\
NT-proBNP $(\mathrm{pg} / \mathrm{ml})$ & $1655.5 \pm 1558.1$ & $965.3 \pm 848.9$ & 0.036 \\
TC $(\mathrm{mmol} / \mathrm{L})$ & $4.88 \pm 1.02$ & $4.54 \pm 1.05$ & 0.591 \\
TG $(\mathrm{mmol} / \mathrm{L})$ & $1.54 \pm 1.06$ & $1.62 \pm 0.65$ & 0.759 \\
HDL $(\mathrm{mmol} / \mathrm{L})$ & $1.10 \pm 0.31$ & $1.01 \pm 0.24$ & 0.417 \\
LDL $(\mathrm{mmol} / \mathrm{L})$ & $2.86 \pm 0.76$ & $2.75 \pm 0.92$ & 0.552 \\
FBG $(\mathrm{mmol} / \mathrm{L})$ & $5.93 \pm 1.34$ & $6.21 \pm 1.73$ & 0.153 \\
\hline
\end{tabular}

group (33 patients), and STEMI without OSAHS (O-) group (42 patients). All clinical data of the patients were collected and analyzed. The project was approved by the ethical committee of the hospital and in accordance with the Helsinki Declaration of 1975. All written informed consents were obtained from the patients or their guardians.

There were 63 men and 12 women. The mean age of the 75 patents was $56.7 \pm 11.6$ years (range: $33-76$ ), and the mean body mass index (BMI) was $25.37 \pm 3.02 \mathrm{~kg} / \mathrm{m}^{2}$. Emergency coronary angiography, overnight oximetry, and evaluation of Epworth sleepiness score (ESS) (12) were performed in all patients.

\section{Diagnostic criteria for STEMI (13)}

At least one of the cardiac biochemical markers (cardiac troponin I or T) beyond $99 \%$ of upper limit of the normal value, and at least accompanied by one of the following changes: 1 ) symptoms of myocardial ischemia; 2) new myocardial ischemia informed by electrocardiogram (new ST segment elevation in two consecutive leads: men $\geq 0.2 \mathrm{mV}$ or women $\geq 0.15 \mathrm{mV}$ in $\mathrm{V} 2 \sim \mathrm{V} 3$ leads, or $\geq 0.1 \mathrm{mV}$ in other leads, or left bundle branch block); 3) pathological Q wave; 4) emerging lost of survival myocardium or regional wall motion abnormality.

\section{Selection criteria}

Patients with STEMI who were hospitalized within $12 \mathrm{~h}$ and emergency coronary angiography was performed to open the obstructed blood vessels within $1 \mathrm{~h}$ after admission.

\section{Exclusion criteria}

1) Accompanied by severe hepatic or renal inadequacy, pulmonary diseases (asthma, chronic obstructive pulmonary disease, diffuse pulmonary disease), or other cardiac diseases (valvular disease, congenital heart disease, cardiomyopathy); 2) acute left or right cardiac insufficiency; 3) treated by oxygen therapy or CPAP within one month; 4) taking hypnagogue or central stimulants long-term or withdrawal within 1 week; 5) with apoplectic history or central sleep apnea within one month; 6) long severe alcohol abuse (more than 10 years).

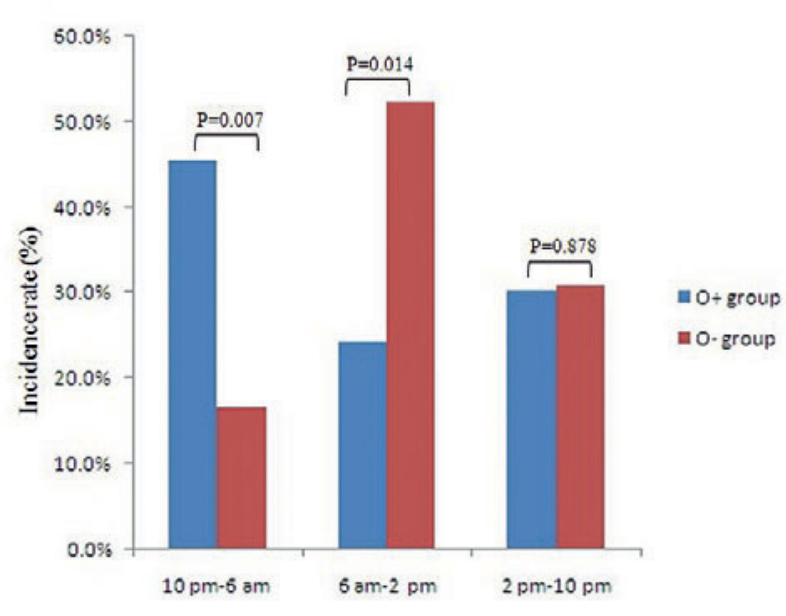

Fig. 1. Comparison in time of AMI occurrence between the two groups.

\section{Statistical analysis}

Statistical analysis was conducted with the SPSS software package (version 13.0, SPSS, Chicago, IL). Quantitative data was presented as the mean \pm standard deviation (SD). Categorical variables were compared to the chi-square test (Fisher's exact test) and continuous variables were compared to the Student's t-test. The relationship between ODI and Gensini Score was analyzed by a simple linear regression analysis. The relationship between OSAHS and clinical parameters was analyzed by a binary logistic regression analysis. For all tests, the $p$ value $<0.05$ was considered as statistically significant.

\section{Results}

\section{Differences between the two groups}

Demographic data

As shown in the Table 1, there was no statistical difference in sex, age, BMI, and time to therapy between the two groups ( $p$ $>0.05$ ). While compared to the $\mathrm{O}^{-}$group, the incidence rate of hypertension was significantly higher in the $\mathrm{O}^{+}$group $(\mathrm{p}=0.036)$.

\section{Time of AMI occurrence}

As shown in the Figure 1, AMI mainly occurred from $10 \mathrm{pm}$ to 6 am in the $\mathrm{O}^{+}$group (45.5\%), while AMI mainly occurred from 6 am to 2 pm in the $\mathrm{O}^{-}$group (52.3\%).

\section{Laboratory examination}

As shown in Table 2, the peak of serum creatine kinase (CK), high-sensitivity C-reactive protein (hs-CRP), and N-terminal Probrain natriuretic peptide (NT-proBNP) were significantly increased in the $\mathrm{O}^{+}$group compared to the $\mathrm{O}^{-}$group $(\mathrm{p}<0.05)$. However, there was no statistical difference in serum total cholesterol (TC),

Tab. 3. Comparison of ultraphonics data between the two groups.

\begin{tabular}{lccc}
\hline Characteristics & $\mathrm{O}^{+}$group $(\mathrm{n}=33)$ & $\mathrm{O}^{-}$group $(\mathrm{n}=42)$ & $\mathrm{p}$ value \\
\hline LVEF $(\%)$ & $48.5 \pm 4.1$ & $52.2 \pm 4.7$ & 0.009 \\
LVFS $(\%)$ & $27.2 \pm 3.8$ & $29.0 \pm 3.2$ & 0.026 \\
LVEDI $(\mathrm{ml} / \mathrm{m} 2)$ & $56.4 \pm 10.9$ & $51.5 \pm 6.6$ & 0.020 \\
\hline
\end{tabular}


Tab. 4. Comparison of ESS, ODI and overnight oximetry between the two groups.

\begin{tabular}{lccc}
\hline Characteristics & $\mathrm{O}^{+}$group $(\mathrm{n}=33)$ & $\mathrm{O}^{-}$group $(\mathrm{n}=42)$ & $\mathrm{p}$ value \\
\hline ESS & $15.3 \pm 3.6$ & $4.5 \pm 4.3$ & 0.009 \\
ODI & $22.2 \pm 8.0$ & $5.7 \pm 3.1$ & $<0.001$ \\
SpO2min (\%) & $77.2 \pm 8.4$ & $93.5 \pm 3.9$ & 0.028 \\
\hline
\end{tabular}

Tab. 5. Binary logistic regression analysis of LVEF.

\begin{tabular}{lccc}
\hline Characteristics & OR & $95 \%$ CI & p value \\
\hline CK & 3.6 & $2.7-16.2$ & 0.001 \\
hs-CRP & 2.2 & $1.9-10.8$ & 0.022 \\
NT-proBNP & 2.3 & $1.6-4.9$ & 0.037 \\
OSAHS & 5.8 & $1.8-21.3$ & 0.008 \\
\hline
\end{tabular}

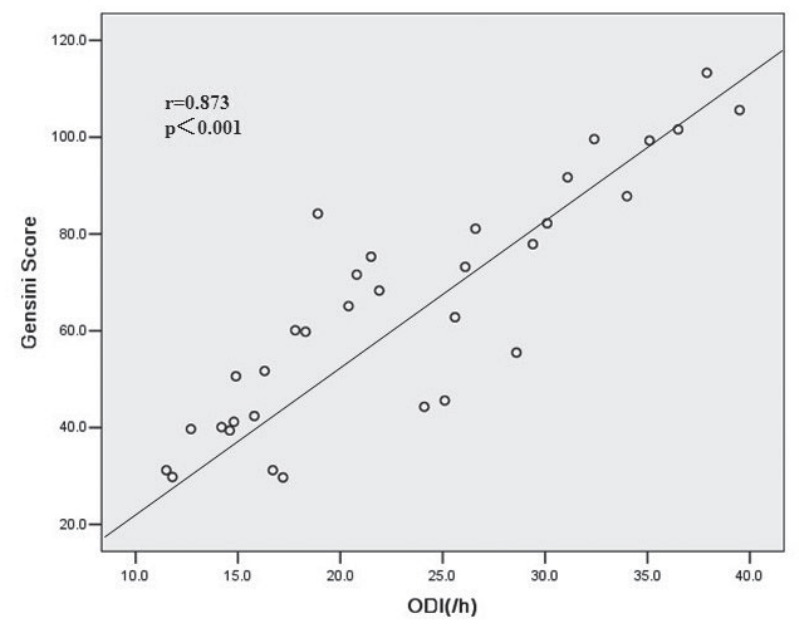

Fig. 2. Correlation of ODI and Gensini Score.

triglyceride (TG), high density lipoprotein (HDL), low density lipoprotein (LDL), and fasting serum glucose (FBG) between the two groups $(\mathrm{p}>0.05)$.

\section{Cardiac ultrasonic inspection}

As shown in the Table 3, the left ventricle end-diastolic volume index (LVEDVI) was significantly increased in the $\mathrm{O}^{+}$group compared to the $\mathrm{O}^{-}$group, while the left ventricular ejection fraction (LVEF) and the left ventricular fractional shortening (LVFS) was significantly decreased $(\mathrm{p}<0.05)$.

\section{ESS, ODI and overnight oximetry}

As shown in the Table 4, the ESS and ODI were significantly higher in the $\mathrm{O}^{+}$group compared to the $\mathrm{O}^{-}$group, while the minimum saturation of blood oxygen $\left(\mathrm{SpO}_{2 \min }\right)$ was significantly lower $(\mathrm{p}<0.05)$.

\section{Regression analysis}

The simple linear regression analysis showed that ODI was positively correlated with Gensini Score $(r=0.873, p<0.001)$ (Fig. 2). Also, the binary logistic regression analysis showed that serum CK, hs-CRP, NT-proBNP, and OSAHS were independently associated with left ventricular insufficiency (LVI), and the incidence of LVI in the $\mathrm{O}^{+}$group was 5.8 times higher than the $\mathrm{O}^{-}$group (Tab. 5).

\section{Discussion}

Generally, OSAHS always co-existed with CAD, and they have many identical risk factors $(5,14)$. Weiss et al $(15)$ reported that the morbidity rate in patients with OSAHS (23.8\% accompanied by ischemic heart disease) is 3.4 times higher than in the control group. Shahar et al (16) reported that almost $16 \%$ of OSAHS patients have concomitantly CAD, and OSAHS is an independent risk factor of CAD. The results of Schafer et al (17) showed that about $50 \%$ of OSAHS patients had coronary artery pathological changes that were confirmed by coronary arteriography, and $50 \%$ of CAD patients were complicated with sleep apnea-hypopnea syndrome (SAHS). Mooe et al (18) also reported that $39 \%$ of patients were complicated with sleep-disordered breathing in men with CAD. Further, Hung et al (19) demonstrated that obstructive sleep apnea (OSA) is an independent risk factor of myocardial infarction (MI), and the incidence rate of MI is increased with the increase of the extent of OSA. All of these studies indicated that coronary artery pathological changes were prone to develop and aggravate in patients with OSAHS, and OSAHS was closely associated with the initiation, progression, and decrease of cardiovascular disease.

In the present study, the clinical characteristics of patients withAMI complicated with OSAHS were analyzed, and the effect of OSAHS on the cardiovascular system was detected. The results showed that the incidence rate of OSAHS in patients with AMI was $44.0 \%$, which was in agreement with the reports of Hung (29\%) et al (19).

As we know, the incidence rate of acute cardiovascular events in normal people is significantly higher between 6 am-12 am than in other time. However, the results were opposite in patients with OSAHS (20). Gami et al (21) reported that the incidence rate of sudden cardiac death in patients with OSA was $46 \%$, and in normal people was $16 \%$. The patients with sudden cardiac death always possess a higher apnea hypopnea index (AHI) at 12 pm-6 am. Kuniyoshi et al (22) also reported that the incidence rate of MI in OSA patients from 12 pm to 6 am was $32 \%$, and in non-OSA patients from $12 \mathrm{pm}$ to 6 am was $7 \%$. While from 6 am to $12 \mathrm{am}$, the incidence rates were $17 \%$ and $47 \%$. In this study, the results were in agreement with the studies mentioned above. The supposed reason was that OSA can induce severe disorder of autonomic nervous function, hemodynamics, humoral regulation and hematological regulation.

Gensini Score is the golden standard for the judgment of the position, number and stenotic degree of affected blood vessels caused by coronary atherosclerosis (11). Our results showed that Gensini Score was paralleled with ODI, and OSAHS was an independent prognostic factor of $\mathrm{CAD}$, which was in agreement with the results of Hayashi et al (23).

Besides, numerous studies have demonstrated that serum CK, hs-CRP, NT-proBNP might play important roles in the development of cardiovascular disease in patients with OSAHS. Shamsuzzaman et al (24) reported that the CRP level was significantly higher in patients with OSA in comparison with the control, and a regression analysis showed that CRP was independently associated with OSA. Sano et al (25) reported that hs-CRP was positively correlated with atherosclerotic plaque rupture and thrombosis in patients with MI. Panteghini et al (26) also reported that serum CK-MB 
and BNP were negatively correlated with LVEF in nonage and three months later in patients with AMI. Our results showed that serum CK, hs-CRP, and NT-proBNP were significantly increased in the $\mathrm{O}^{+}$group compared to the $\mathrm{O}^{-}$group, and all of them were independently associated with LVI. This may be because OSAHS is prone to induce ischemical reperfusion injury, which further results in myocardial cells apoptosis and myocardium necrosis.

Furthermore, our results showed that the LVEDVI was significantly increased in the $\mathrm{O}^{+}$group compared to the $\mathrm{O}^{-}$group, while the LVEF and the LVFS were significantly decreased. Notably, the incidence rate of LVI in $\mathrm{O}^{+}$group was 5.8 times higher than the $\mathrm{O}^{-}$ group, which means that OSAHS was closely associated with AMI.

\section{Conclusion}

AMI mainly occurred from $10 \mathrm{pm}$ to 6 am in AMI patients with OSAHS, and the incidence of LVI was significantly higher than in AMI patients without OSAHS. Also, OSAHS might play important roles in the development and progression of AMI. However, this was a retrospective study and only electrocardiogram, serological biochemical markers, and ultrasound was used; more sensitive and rigorous detection methods are needed. In addition, further investigations are imperative to identify the molecular mechanisms how OSAHS promotes the development and progression of AMI.

\section{References}

1. Somers VK, White DP, Amin R, Abraham WT, Costa F, Culebras A et al. Sleep apnea and cardiovascular disease: an American Heart Association/american College of Cardiology Foundation Scientific Statement from the American Heart Association Council for High Blood Pressure Research Professional Education Committee, Council on Clinical Cardiology, Stroke Council, and Council On Cardiovascular Nursing. In collaboration with the National Heart, Lung, and Blood Institute National Center on Sleep Disorders Research (National Institutes of Health). Circulation 2008; 118 (10): $1080-1111$.

2. Banno K, Shiomi T, Sasanabe R, Otake K, Hasegawa R, Maekawa M et al. Sleep-disordered breathing in patients with idiopathic cardiomyopathy. Circ J 2004; 68 (4): 338 - 342.

3. Racineux JL. Epidemiological definition of obstructive sleep apnea syndrome. Rev Neurol (Paris) 2003; 159 (11 Suppl): 6S - 88S.

4. Lacassagne L, Didier A, Doussau S, Murris-Espin M, Birot P, Charlet JP et al. Results of 248 patients with sleep apnea syndrome treated by continuous positive pressure ventilation between 1990 and 1995. A study of compliance and outcome of the apnea-hypopnea index. Rev Mal Resp 2000; 17 (2): 467 - 474.

5. Kato M, Adachi T, Koshino Y, Somers VK. Obstructive sleep apnea and cardiovascular disease. Circulat J 2009; 73 (8): 1363 - 1370.

6. Young T, Palta M, Dempsey J, Skatrud J, Weber S, Badr S. The occurrence of sleep-disordered breathing among middle-aged adults. N Engl J Med 1993; 328 (17): 1230 - 1235.

7. Huang SG, Li QY. Prevalence of obstructive sleep apnea-hypopnea syndrome in Chinese adults aged over $30 \mathrm{yr}$ in Shanghai. Zhonghua Jie $\mathrm{He} \mathrm{He}$ Hu Xi Za Zhi 2003; 26 (5): 268 - 272.

8. Prabhakar NR. Sleep apneas: an oxidative stress? Am J Respir Crit Care Med 2002; 165 (7): $859-860$.
9. Rodenstein DO, D’Odemont JP, Pieters T, Aubert-Tulkens G. Diurnal and nocturnal diuresis and natriuresis in obstructive sleep apnea. Effects of nasal continuous positive airway pressure therapy. Am Rev Resp Dis 1992; 145 (6): $1367-1371$.

10. Peker Y, Hedner J, Kraiczi H, Loth S. Respiratory disturbance index: an independent predictor of mortality in coronary artery disease. Am J Resp Crit Care Med 2000; 162 (1): 81 - 86.

11. Gensini GG. A more meaningful scoring system for determining the severity of coronary heart disease. Am J Cardiol 1983; 51 (3): 606.

12. Knutson KL, Rathouz PJ, Yan LL, Liu K, Lauderdale DS. Stability of the Pittsburgh Sleep Quality Index and the Epworth Sleepiness Questionnaires over 1 year in early middle-aged adults: the CARDIA study. Sleep 2006; 29 (11): 1503 - 1506.

13. Bybee KA, Kara T, Prasad A, Lerman A, Barsness GW, Wright RS et al. Systematic review: transient left ventricular apical ballooning: a syndrome that mimics ST-segment elevation myocardial infarction. Ann Intern Med 2004; 141 (11): $85-65$.

14. Lavie CJ, Milani RV, Ventura HO. Obesity and cardiovascular disease: risk factor, paradox, and impact of weight loss. J Am Coll Cardiol 2009; 53 (21): 1925 - 1932.

15. Weiss JW, Launois SH, Anand A, Garpestad E. Cardiovascular morbidity in obstructive sleep apnea. Prog Cardiovasc Dis 1999; 41 (5): 367 - 376.

16. Shahar E, Whitney CW, Redline S, Lee ET, Newman AB, Javier NF et al. Sleep-disordered breathing and cardiovascular disease: crosssectional results of the Sleep Heart Health Study. Am J Resp Crit Care Med 2001; 163 (1): $19-25$.

17. Schafer H, Kohler U, Ploch T, Peter JH. Coronary heart disease and upper airway obstruction. J Sleep Res 1995; 4 (S1): 185 - 189.

18. MooeT,Rabben T, Wiklund U,Franklin KA, Eriksson P. Sleep-disordered breathing in men with coronary artery disease. Chest 1996; 109 (3): 659-663.

19. Hung J, Whitford EG, Parsons RW, Hillman DR. Association of sleep apnoea with myocardial infarction in men. Lancet 1990; 336 (8710): 261 - 264.

20. Cohen MC, Rohtla KM, Lavery CE, Muller JE, Mittleman MA. Meta-analysis of the morning excess of acute myocardial infarction and sudden cardiac death. Am J Cardiol 1997; 79 (11): 1512 - 1516.

21. Gami AS, Howard DE, Olson EJ, Somers VK. Day-night pattern of sudden death in obstructive sleep apnea. N Engl J Med 2005; 352 (12): $1206-1214$.

22. Kuniyoshi FH, Garcia-Touchard A, Gami AS, Romero-Corral A, van der Walt $\mathbf{C}$, Pusalavidyasagar $\mathbf{S}$ et al. Day-night variation of acute myocardial infarction in obstructive sleep apnea. J Am Coll Cardiol 2008; 52 (5): $343-346$.

23. Hayashi M, Fujimoto K, Urushibata K, Uchikawa S, Imamura H, Kubo K. Nocturnal oxygen desaturation correlates with the severity of coronary atherosclerosis in coronary artery disease. Chest 2003; 124 (3): 936-941.

24. Shamsuzzaman AS, Winnicki M, Lanfranchi P, Wolk R, Kara T, Accurso $\mathrm{V}$ et al. Elevated C-reactive protein in patients with obstructive sleep apnea. Circulation 2002; 105 (21): 2462 - 2464.

25. Sano T, Tanaka A, Namba M, Nishibori Y, Nishida Y, Kawarabayashi T et al. C-reactive protein and lesion morphology in patients with acute myocardial infarction. Circulation 2003; 108 (3): 282 - 285.

26. Panteghini M, Cuccia C, Bonetti G, Pagani F, Giubbini R, Bonini E. Rapid determination of brain natriuretic peptide in patients with acute myocardial infarction. Clin Chem Lab Med 2003; 41 (2): 164 - 168.

Received July 10, 2010. Accepted June 2012. 